\title{
Healing the web of life: on the meaning of environmental and health equity
}

\author{
Arturo Escobar ${ }^{1}$
}

Received: 13 June 2018/Revised: 2 July 2018 / Accepted: 4 August 2018/Published online: 10 August 2018

(C) Swiss School of Public Health (SSPH+) 2018

More than at any other point in history, health is emerging as a crucial domain of thought and action in the wake of the combined crises of climate, energy, poverty and inequality. This goes beyond the disappearance of species and the increasingly destructive effects of climate change; it involves the disruption of human sociality, the breakdown of social relations, the proliferation of wars and violence, abhorrent inequality and the difficulty young people face in crafting lives of meaning. So much suffering and devastation shows up in the health of bodies, communities, landscapes and ecosystems. Confronting such a crisis imaginatively and effectively requires looking deeply into the world and perceiving anew the devastation that surrounds us, reaching out to our innermost selves for the strength to face it with utmost courage and hope. We need to foster the desire for a better, and different, world. Health, like ecology, is a fundamental space for pursuing this goal.

There is hardly any need to rehearse the markers of the blatant inequality of today's economic system, though it's worth mentioning the 2017 Oxfam report. Its press release headline says it all: "Richest 1 percent bagged 82 percent of wealth created last year-poorest half of humanity got nothing". This corroborates what progressive social scientists have been denouncing for some time: the accelerating trends toward widening inequality of wealth and income, between and within countries. According to sociologist Sassen (2014), systematic expulsions (of people from their territories, or nonhuman species from the biosphere, of local economies from the economy, of the poor from society through massive incarceration) have become the central logic of global capitalism. Underneath this

This editorial is part of the special issue "Environmental and health equity".

Arturo Escobar

aescobar@email.unc.edu

1 University of North Carolina at Chapel Hill, Chapel Hill, NC, USA "savage sorting"- the simple, brutal result of progressively complex processes of power-one finds deepening inequities of all types.

No other sphere of social life reveals the depth of the sharply increasing levels of social inequity and ecological devastation more than health. This is particularly true if one adopts the view of some health critics and activists, according to which health is the result of the interaction between elements stemming from an entire range of systems (biophysical, economic, political, cultural, environmental, spiritual). According to this holistic perspective, health is an emergent property of the dynamic interaction of the self-organizing networks entailed in these systems, not the result of a few factors, such as genes.

Adopting this perspective, one reaches the conclusion that what needs to be healed is the entire system of relations, not just bodies or ecosystems. "Ecological health" might be a place holder for this complexity. As complexity theorist Brian Goodwin states, it is necessary to transcend the conflict "between the management of health on the one hand, and healthy living in communities, on the other" (Goodwin 2007: 50). For this author, there are direct connections between the body and emotions, and between physiology, feelings and meanings, underscoring the healing power of communal and relational approaches. Healing, in other words, needs to happen in place and community.

The notion that living is deeply relational-and, hence, that any strategy to promote or restore health needs to take this systemic nature into account-is supported by the cosmovisions or worldviews of many indigenous people. Today's dominant approaches-increasingly corporatized-run in the opposite direction; as such, no matter how many "miracle cures" they find, they might at best reduced disease, but not produce genuine, lasting health. A pluriversal approach would incorporate the diverse knowledge of the multiple worlds that inhabit the planet, particularly those that are attuned to social justice and the systemic character of life. Contrary to established 
discourses of sustainable development, what needs to be sustained is the entire network of relations that create life and community. Health must come to be seen as a contributor to weaving effectively the web of life, within an ecological conception of health and equity. This would involve providing for life's necessities, but also life's other, equally real, dimensions, from feelings and emotions to spirituality.

There is an utter imbalance between two worldviews at present: the dominant view based on the separation between body and mind, subject and object, individual and community (the ontology of separation predominant in the West, at the basis of modern health systems), on the one hand and, on the other, ontologies or worldviews that acknowledge the radical interdependence of everything that exists. Moving in the direction of ontological equity between these worldviews requires nothing less than a civilizational transition. Herein lies the greatest challenge facing the concept of "ecological health".

\section{Compliance with ethical standards}

Conflict of interest The author declares that he has no conflicts of interest related to this Editorial.

\section{References}

Goodwin B (2007) Nature's due: healing our fragmented culture. Floris Books, Edinburgh

Sassen S (2014) Expulsions: brutality and complexity in the global economy. Harvard University Press, Cambridge 